\title{
Transtemporal amygdalohippocampectomy: a novel minimally-invasive technique with optimal clinical results and low cost
}

\author{
Amigdalo-hipocampectomia transtemporal: técnica minimamente invasiva com ótimos \\ resultados clínicos e baixo custo \\ Juan Antonio Castro Flores' ${ }^{1}$ Felipe Hada Sanders' ${ }^{1}$ Eberval Gadelha Figueiredo ${ }^{1}$ Manoel Jacobsen Teixeira
}

\begin{abstract}
Mesial temporal sclerosis creates a focal epileptic syndromethat usually requires surgical resection of mesial temporal structures. Objective: To describe a novel operative technique for treatment of temporal lobe epilepsy and its clinical results. Methods: Prospective case-series at a single institution, performed by a single surgeon, from 2006 to 2012 . A total of 120 patients were submitted to minimally-invasive keyhole transtemporal amygdalohippocampectomy. Results: Of the patients, $55 \%$ were male, and $85 \%$ had a right-sided disease. The first 70 surgeries had a mean surgical time of 2.51 hours, and the last 50 surgeries had a mean surgical time of 1.62 hours. There was 3.3\% morbidity, and 5\% mild temporal muscle atrophy. There was no visual field impairment. On the Engel Outcome Scale at the two-year follow-up, $71 \%$ of the patients were Class I, $21 \%$ were Class II, and 6\% were Class III. Conclusion: This novel technique is feasible and reproducible, with optimal clinical results.
\end{abstract}

Keywords: anterior temporal lobectomy; epilepsy, temporal lobe; epilepsies, partial

\section{RESUMO}

Aesclerose mesial temporalé uma síndrome epiléptica focal que requer ablação de estruturas mesiais temporais. Objetivo: Descrever e padronizar a técnica operatória e resultados clínicos. Métodos: Série prospectiva de casos de uma única instituição, realizadas por um único cirurgião, de 2006 a 2012. 120 doentes foram submetidos a amigdalo-hipocampectomia transtemporal por acesso mínimo (keyhole). Resultados: 55\% eram do sexo masculino, $85 \%$ apresentavam doença do lado direito. As primeiras 70 cirurgias tiveram um tempo cirúrgico médio de 2,51 horas, e as últimas 50 cirurgias tiveram um tempo cirúrgico médio de 1,62 horas. Houve morbidade de 3,3\%. 5\% dos doentes apresentaram atrofia leve de músculo temporal. O controle das convulsões foi avaliado com a Escala de Engel no segundo ano de pós operatorio ,71\% eram Classe I, 21\% Classe II, 6\% Classe III. Conclusão: Esta nova técnica é viável, reprodutível e com resultados clínicos adequados .

Palavras-chave: lobectomia temporal anterior; epilepsia do lobo temporal; epilepsias parciais

Temporal lobe epilepsy (TLE), caused by mesial temporal sclerosis (MTS), is a focal epileptic syndrome that presents a stereotyped clinical picture with a pathological substrate. The epileptogenic focus compromises mesial temporal lobe structures ${ }^{1,2,3,4,5}$. Surgery in patients with TLE refractory to drug therapy allows adequate seizure control in up to $80 \%$ of patients, constituting an effective therapeutic method ${ }^{6,7,8,9,10}$.

There are several techniques described for resection of the mesial structures. Many of these techniques include mobilization of delicate vascular and neural structures through large and invasive approaches, which generate higher morbidity and costs. We have improved the lateral transtemporal surgical corridor, minimizing its disadvantages, reducing visual field defects, and the complications of conventional craniotomy using a minimally-invasive keyhole approach. We describe this technique and report its clinical outcomes.

\section{METHODS}

From January 2006 to December 2012, a total of 120 patients with TLE due to MTS, were operated on by the

'Universidade de São Paulo, Faculdade de Medicina, Hospital das Clínicas, Instituto de Psiquiatria, Divisão de Neurocirurgia Funcional, São Paulo SP, Brasil. Correspondence: Juan Antonio Castro Flores; Div. de Neurocirurgia Funcional, Instituto de Psiquiatria HCFMUSP; Dr. Ovídio Pires de Campos, 785, Cerqueira César; 01060-970 São Paulo SP, Brasil; E-mail: castrocolodro@uol.com.br 
same surgeon (JACF) using a minimally-invasive transtemporal amygdalohippocampectomy. This study was approved by the Ethics Committee (CAPPesq HCFMUSP).

Patients were selected according to the standard protocol of preoperative investigation for temporal lobe epilepsy: 1) Clinical history and physical examination; 2) Video-electroencephalogram (performed on 80 patients); 3) An MRI search for hippocampal atrophy and hippocampal signal enhancement (performed on all patients); 4) Neuropsychological evaluation (performed on all patients); 5) Interictal single photon emission computed tomography with hexamethylpropyleneamine oxime (performed on 23 patients); 6) Evaluation by a multidisciplinary group.

The selection criteria included: findings consistent with TLE and MTS; complex partial seizures; epileptic activity originating in the mesial temporal structures; hippocampal unilateral atrophy with or without hyperintense signal on T2-weighted sequences; ipsilateral temporal hypometabolism or asymmetries in temporal lobe metabolism.

The following data were analyzed: age; gender; laterality; evaluation of the surgical corridor (hippocampal exposure: visualization of the head and body of the hippocampus; the surgeon's comfort evaluated by the maneuverability of the surgical instruments and technical difficulty in resecting the mesial structures); duration of surgery measured from cutaneous incision to completion of cutaneous suture; surgical complications; outcome of seizure control - Engel Outcome Scale after two years; cosmetic results.

All patients were evaluated at regular intervals after surgery (third week, three, 12 and 24 months). A complete neurological examination was performed, including a visual field evaluation.

\section{Statistical analysis}

The series was divided into two groups (group 1, the first 70 patients, and group 2, the last 50 patients). Surgical times were described using means, standard deviation, median and range. The groups were compared using the Student's t-test (with a significance level of 5\%) and the assumption of normal distribution of surgical times in each group (Microsoft Excel 2003 and SPSS 20.0).

\section{Surgical technique Positioning}

The patient was placed under general anesthesia. Their head was positioned with a 40-degree contralateral rotation and deflection, resulting in the zygomatic arch as the highest head point (Figure 1). In the last 30 patients only, silicone cushions were used, without need for rigid cranial fixation.

\section{Incision}

A curvilinear incision was made, following the contour of the hairless skin from the upper rim of the zygomatic arch to the upper temporal line $(5-6 \mathrm{~cm})$. The cutaneous-muscular plane was dissected in a single plane fashion, exposing the squamous temporal bone. The anterior flap of the cutaneous incision had been previously retracted to facilitate angulation of the surgical microscope (Figure 2).

\section{Keyhole craniotomy}

An oval-shaped mini-craniotomy of approximately $2 \mathrm{~cm}$, with the anterior limit at the sphenotemporal suture and the posterior border at the base of the zygomatic temporal process, was performed using only a high-speed drill (Figure 3).

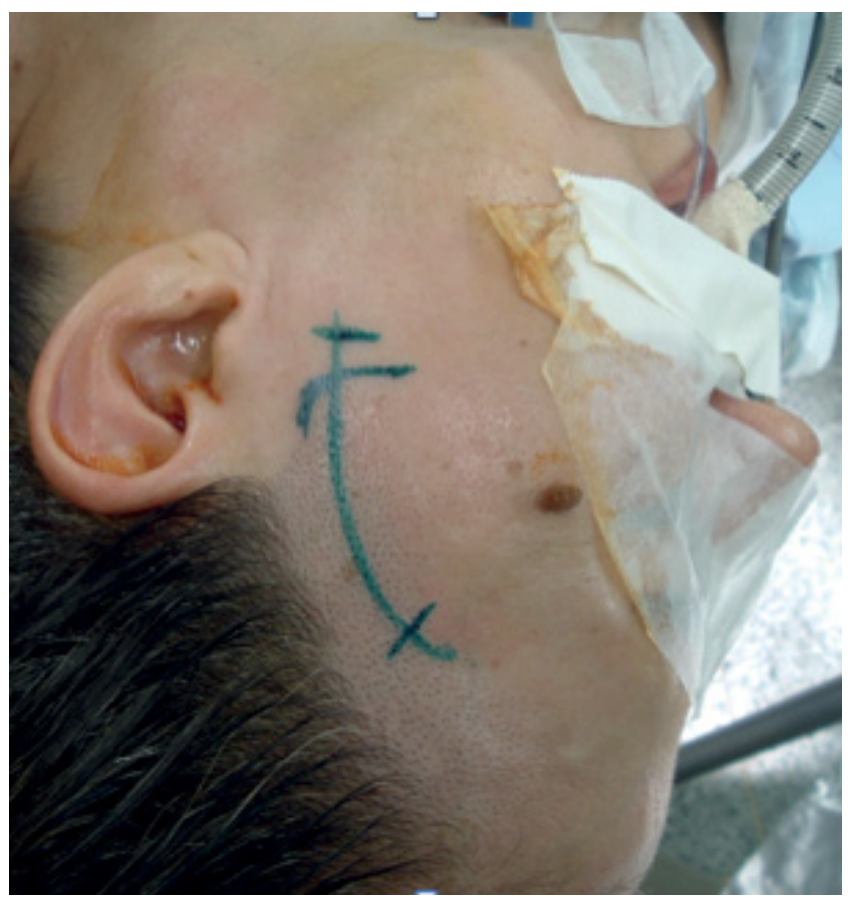

Figure 1. The patient's head is positioned placing the zygomatic arch at the highest point, allowing better visualization of the body and tail of the hippocampus through the surgical corridor in later steps; skin incision marked (5 cm of extension).

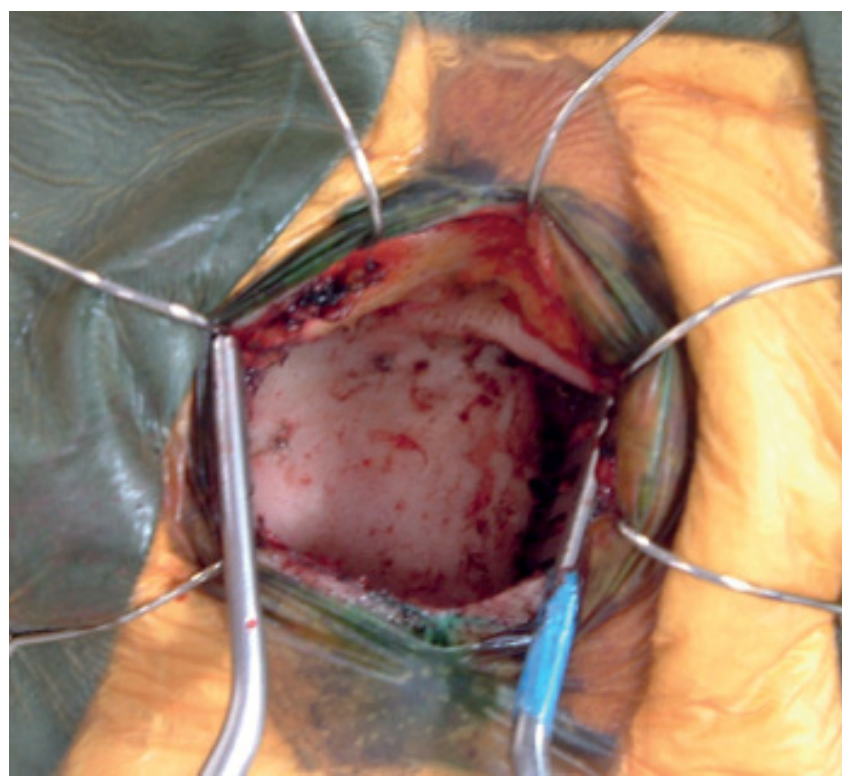

Figure 2. Squamous temporal bone exposure after single plane dissection. 


\section{Dural opening}

The dura was opened in a star shape allowing exposure of only the middle temporal gyrus (Figures 4, 5). The "hippocampal point" usually located $32 \mathrm{~mm}$ cranially to the external auditory canal was identified"1 ${ }^{11}$ The location of the "hippocampal point" should always be confirmed individually for each patient, based on the patient's MRI.

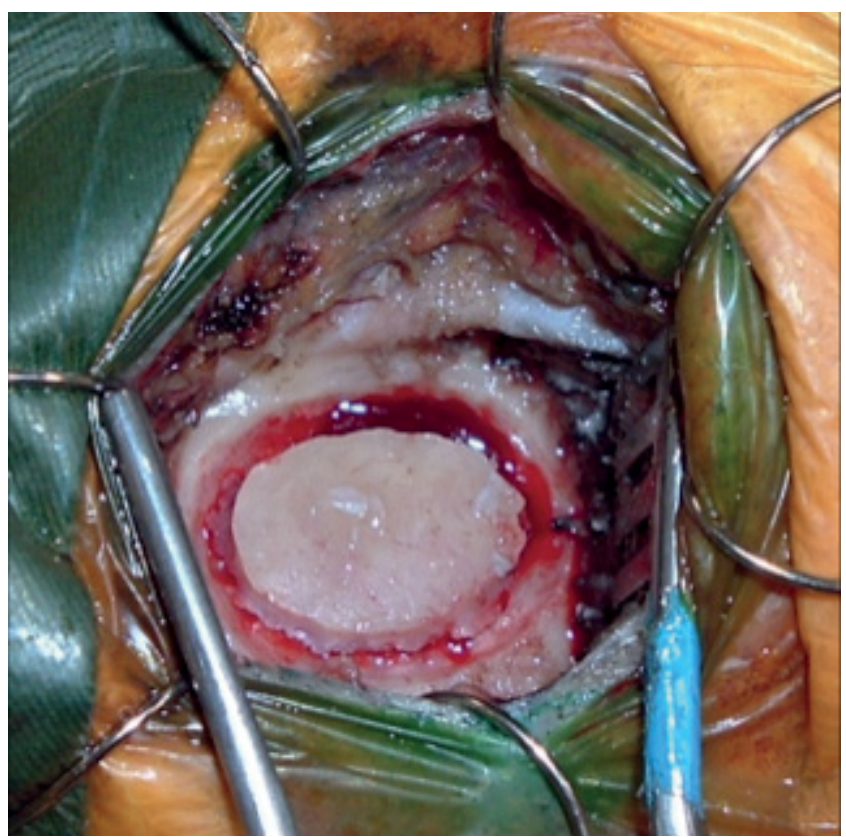

Figure 3. Key-hole craniotomy ( $2 \mathrm{~cm}$ of extension) is centered at the hippocampal point.

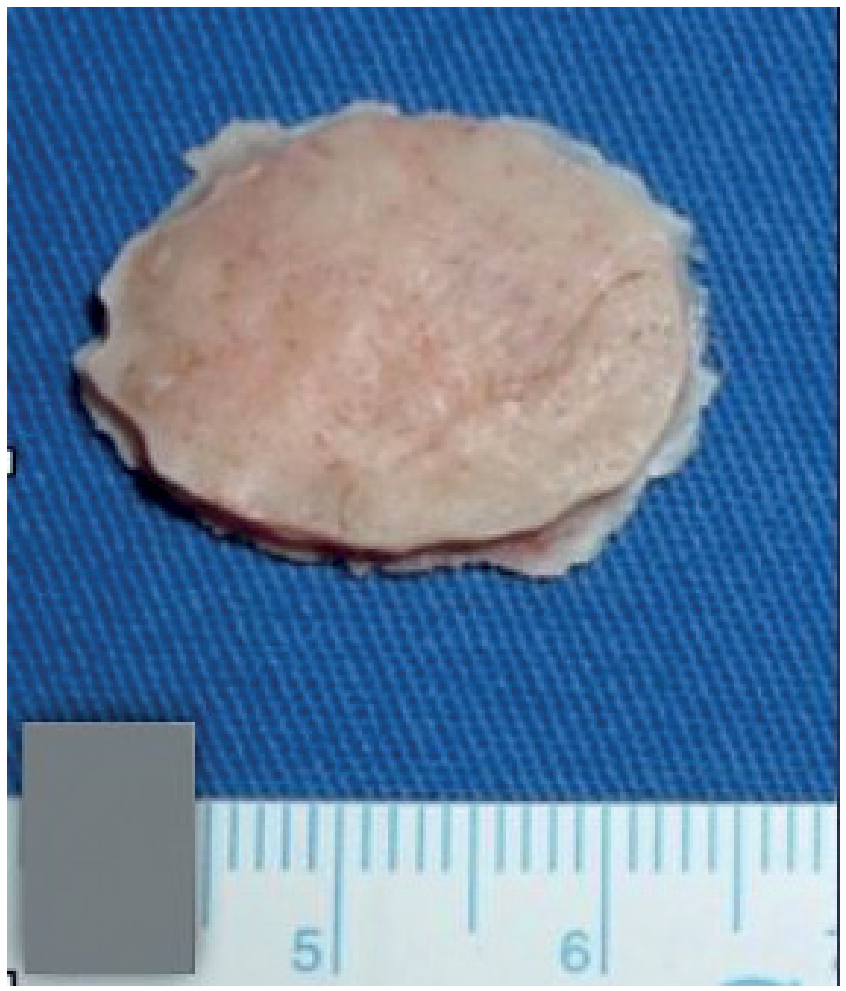

Figure 4. Bone flap measurement.

\section{Exposure of the temporal horn of the lateral ventricle}

A corticectomy was initiated at the "hippocampal point". The pia of the middle temporal gyrus was sectioned. The neocortical layer was removed and the white matter of the middle and inferior temporal gyrus was dissected. The corticectomy had a cylindrical shape with a diameter of $1.5 \mathrm{~cm}$ to 2 $\mathrm{cm}$, performed with the aid of a surgical microscope. Usually, the temporal horn is identified approximately $3 \mathrm{~cm}$ deep from the posterior border of the corticectomy ${ }^{12}$.

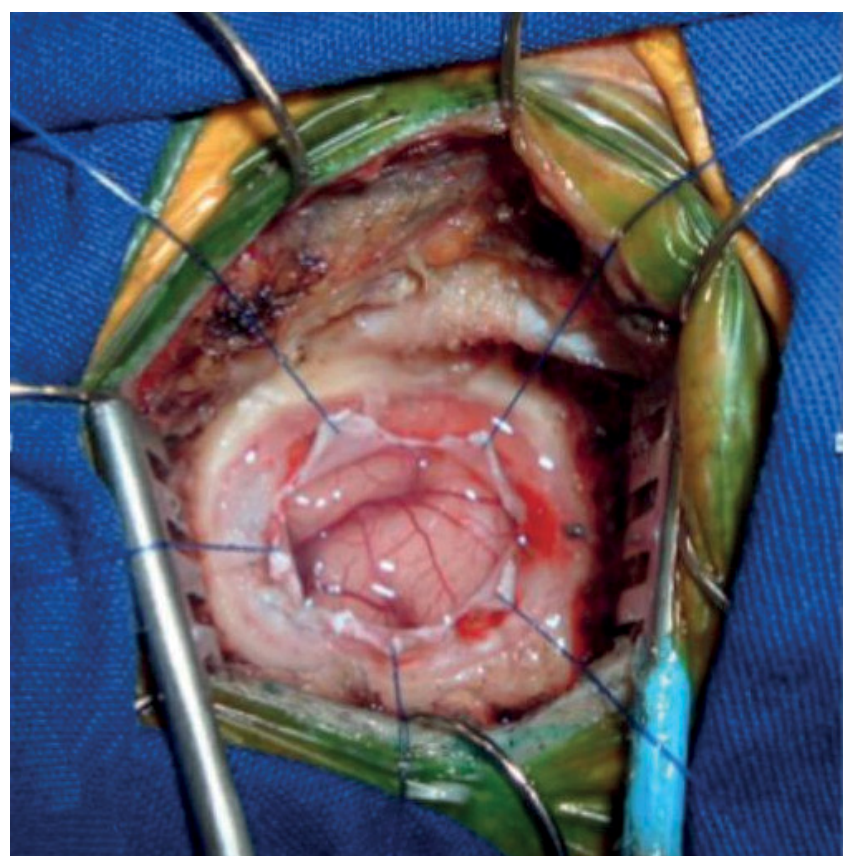

Figure 5. Middle temporal gyrus has been exposed after durotomy.

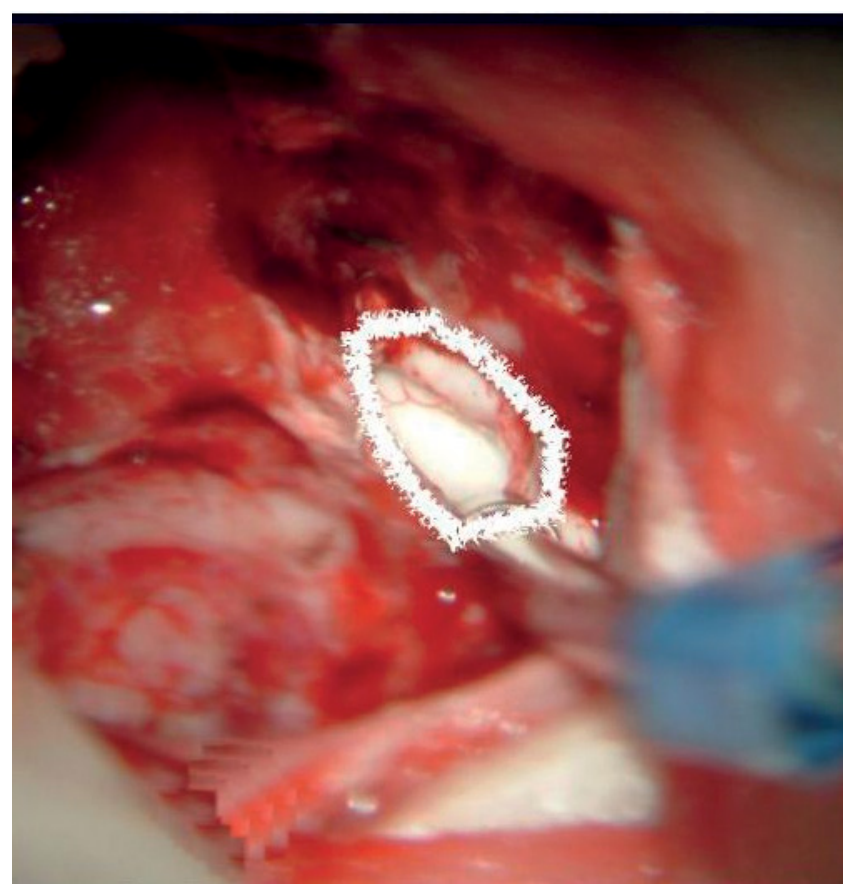

Figure 6. Hippocampus exposure after cylindrical corticectomy and lateral ventricle opening. 
The corticectomy was performed in the lower part of the middle temporal gyrus, avoiding proximity to the superior temporal gyrus, especially in surgeries performed in the dominant hemisphere. The first sign of the temporal horn was the increased vascularization and tissue resistance. If the ventricle was not reached, the direction of dissection was redirected by a few millimeters in the posterior and superior direction (Figure 6).

\section{Resection of amygdala and uncus}

The amygdala and hippocampus were removed using the conventional subpial technique. The posterolateral surface of the amygdala was visible anteriorly and superiorly to the choroid plexus that emerges from the choroidal fissure. The ventricular ceiling plane was used as a parameter for resection of the amygdala. The amygdala was resected until identification of the pia-arachnoid membrane of the underlying Sylvian fissure. The posterosuperior segment of the amygdala was not resected. The removal of the amygdala created a field from the ventricular roof of approximately $7 \mathrm{~mm}$ in extension and $5 \mathrm{~mm}$ deep.

The uncus was resected until the free edge of the tentorium was identified. At this stage, dissection in the medial part had to be avoided in the proximity of the anterior choroidal artery, which occasionally may occupy the entorhinal sulcus (Figure 7).

\section{Resection of the hippocampus and parahippocampus}

Hippocampal resection was initiated with lateral, anterior and medial disconnection. The arteries that feed the hippocampus were cauterized and sectioned, allowing en-bloc resection of the anterior third of the hippocampus and parahippocampus (approximately $2 \mathrm{~cm}$ to $3 \mathrm{~cm}$ in extension). The second-third of the hippocampal body and tail, as well as the remnant of the parahippocampus was resected using micro suction and bipolar cauterization (Figure 8).

\section{Closing}

A watertight closure was performed, using autologous pericranium or temporal fascia. The bone flap was repositioned and fixed with fibrin glue. The muscular, subcutaneous and cutaneous planes were sutured with Nylon 3-0 (Figure 9).

\section{Postoperative follow-up}

All patients had a head CT scan on the first postoperative day to exclude complications (Figure 10). Patients without clinical complications were discharged on the third postoperative day. All patients had close outpatient clinic follow-ups for two years and an MRI after three months (Figure 11).

A total of 120 patients were treated. Gender analysis revealed an equivalent distribution: male $66(55 \%)$ and female 54 (45\%). Ages ranged from 11 years to 68 years (Table 1). Patients with right MTS were the most frequent (85\%) (Table 2).

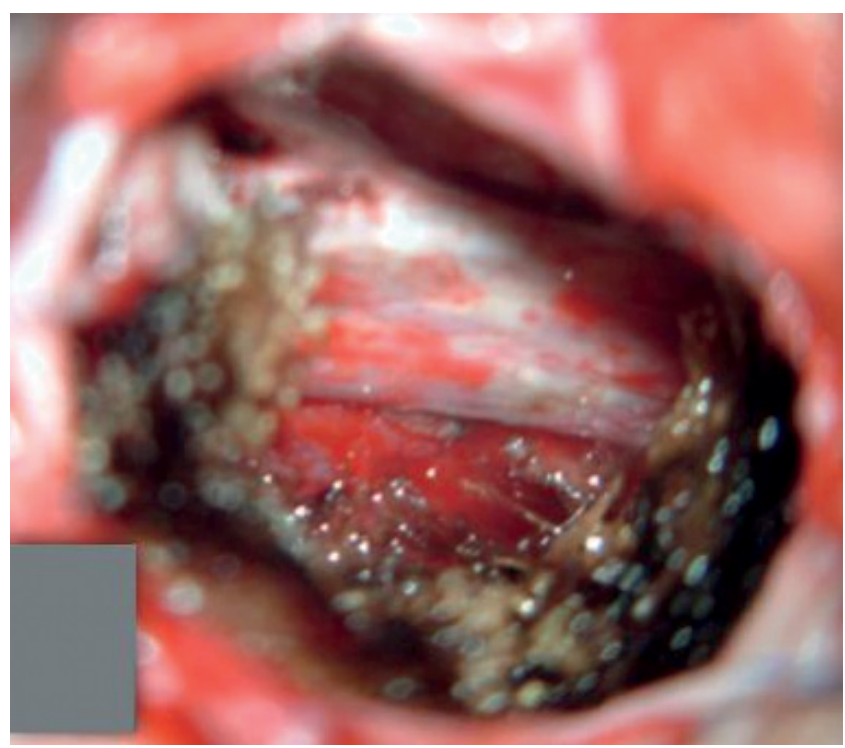

Figure 7. After subpial hippocampus, uncal and parahippocampal resection, the tentorial edge is identified, along the carotid and crural cisterns at the medial edge of the exposure.

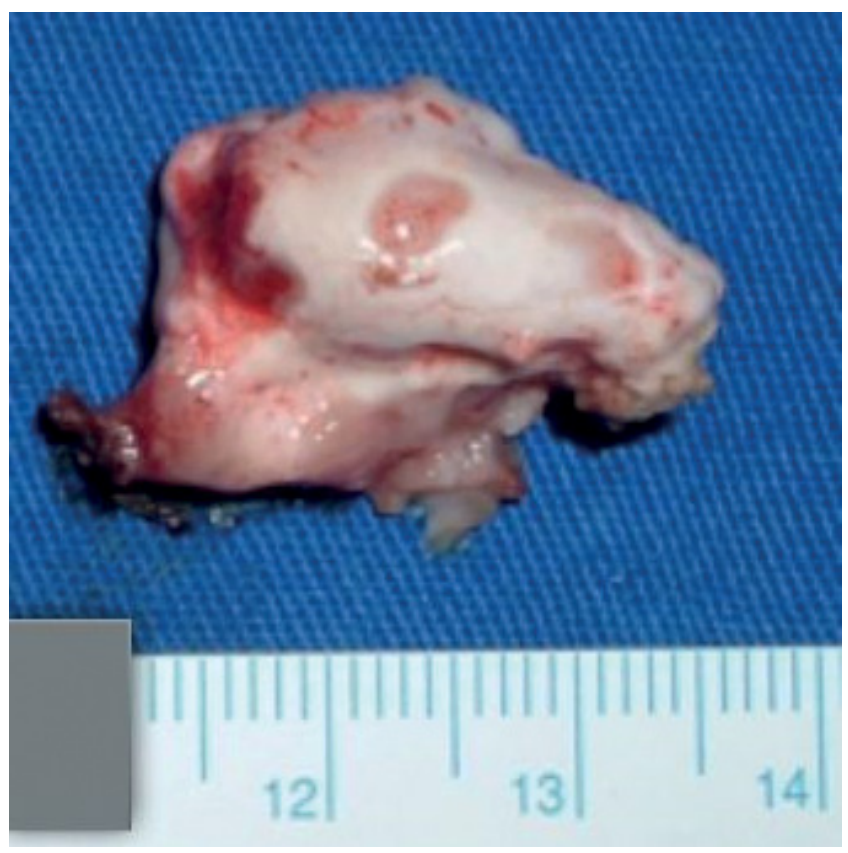

Figure 8. En-bloc resection of anterior third of hippocampus and parahippocampal gyrus.

\section{RESULTS}

Intraoperative evaluation of the surgical corridor was performed, observing the exposure of the head and body of the hippocampus and it was considered adequate in all patients. There were no technical difficulties in the resection of the mesial structures, which may be attributed to the optimized surgical corridor.

The mean duration of surgery in the first 70 patients of this series (group 1) was $2.51+/-0.33$ hours, and in 

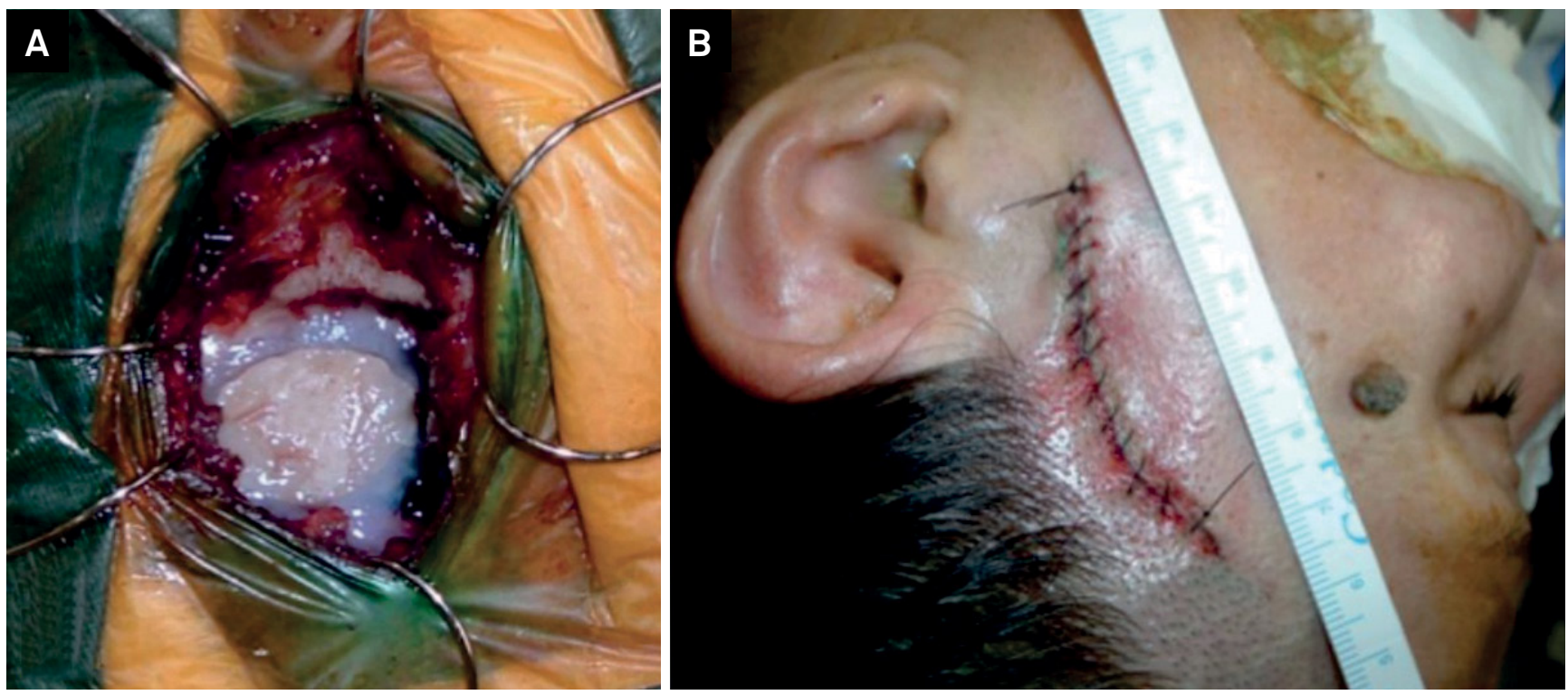

Figure 9. A. The bone flap has been repositioned, fixed with fibrin glue; B. The skin closed with running sutures.

A

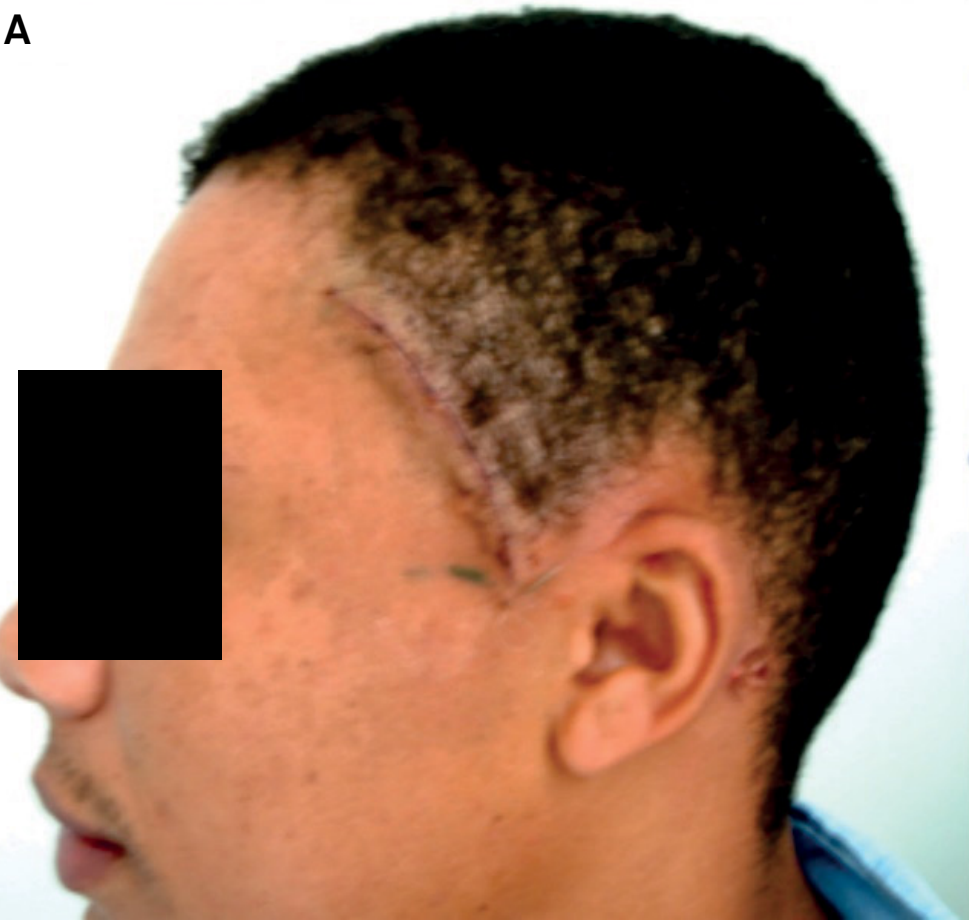

B

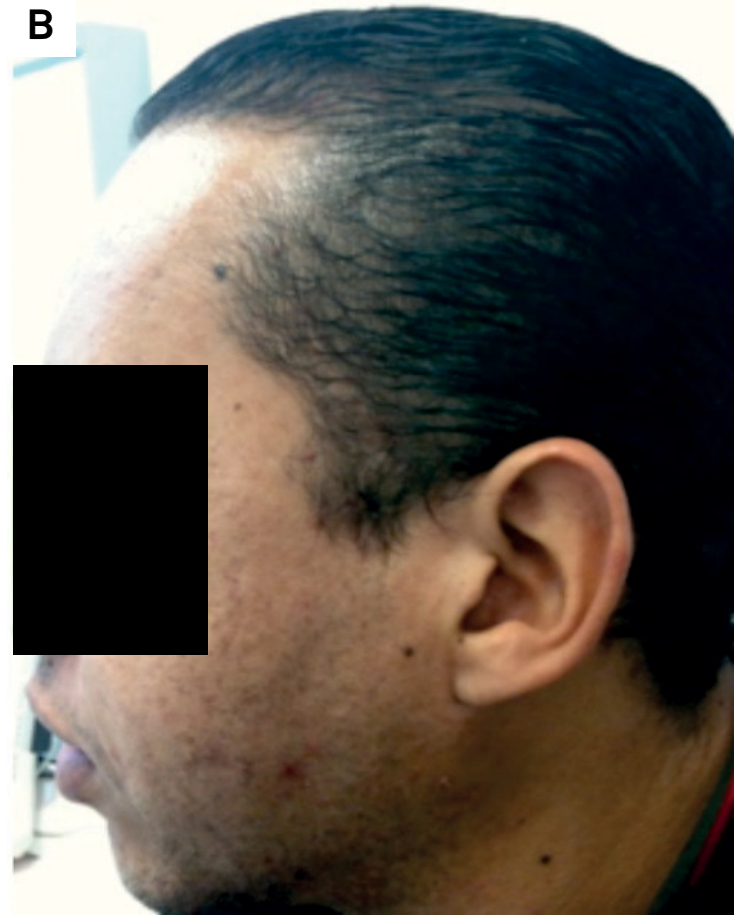

Figure 10. A. Cosmetic effect at hospital discharge; B. And at the two-year follow-up.

the last 50 patients (group 2) it was $1.62+/-0.22$ hours $(\mathrm{p}<0.001)$ (Table 3$)$.

Morbidity was $3.3 \%$. Four patients presented with surgical complications: one with cerebrospinal fluid leakage, one with capsular ischemia, and two with paresis of the oculomotor nerve. No deaths, hemorrhagic complications, postoperative infection or need for blood transfusion were observed in this series (Table 4).

Results for seizure control using the Engel Outcome Scale in the 24 th postoperative month revealed that
86 patients $(71 \%)$ did not have any new seizures (Class I); 26 (21.6\%) had seizure reduction greater than 90\% (Class II); eight (6.6\%) had seizure reduction between $60 \%$ and $90 \%$ (Class III). No patient evolved to Class IV or V (Table 5).

Cosmetic results were evaluated in the 24th postoperative month, and no patient reported aesthetic complaints. In six patients (5\%), mild temporal muscle atrophy measured by asymmetry with the contralateral side was observed (Figure 12). 

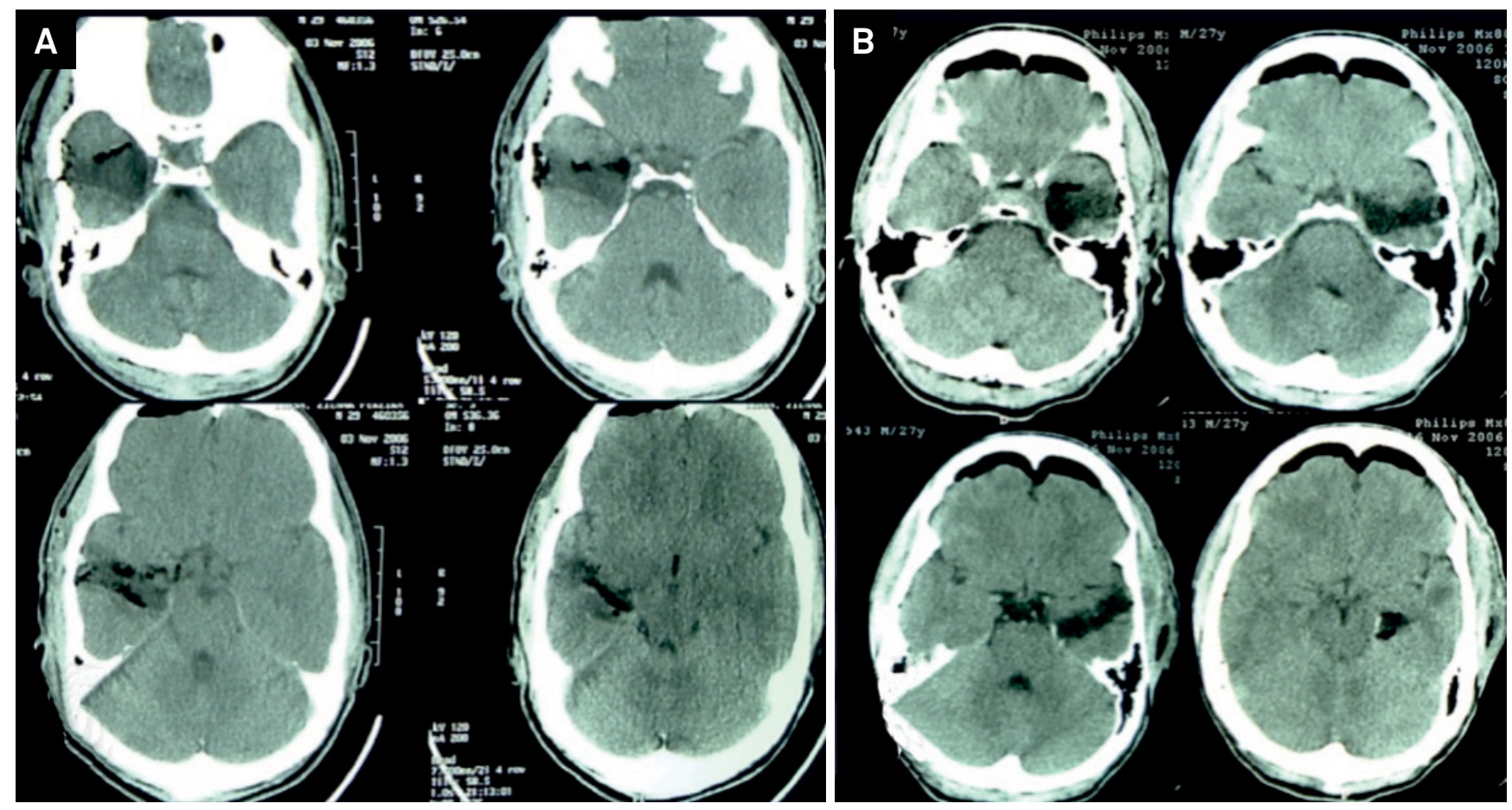

Figure 11. Immediate postoperative head CT, illustrating the mesial structure resection through the minimally-invasive approach.

Table 1. Age distribution.

\begin{tabular}{lc}
\hline Age & $\mathrm{n}$ \\
\hline $11-20$ & 15 \\
$21-30$ & 35 \\
$31-40$ & 40 \\
$41-50$ & 20 \\
$51-60$ & 7 \\
$61-70$ & 3 \\
\hline
\end{tabular}

Table 2. Disease laterality distribution.

\begin{tabular}{lc}
\hline Side & $\mathrm{n}(\%)$ \\
\hline Right & $102(85)$ \\
Left & $18(15)$ \\
Total & 120 \\
\hline
\end{tabular}

Table 3. Comparison of surgery duration between two groups through evaluated with the t-Student-t test.

\begin{tabular}{lccccccc}
\hline Group & Mean & SD & Median & Minimum & Maximum & $\mathrm{N}$ & $\mathrm{p}$ \\
\hline 1 & 2.51 & 0.33 & 2.50 & 2.00 & 3.50 & 70 & - \\
2 & 1.62 & 0.22 & 1.67 & 1.17 & 2.00 & 50 & $<0.001$ \\
Total & 2.14 & 0.53 & 2.17 & 1.17 & 3.50 & 120 & - \\
\hline
\end{tabular}

The patients reported no subjective visual impairment, and no alteration of visual fields was objectively detected after three weeks, or at three, 12 and 24 months.

\section{DISCUSSION}

Epilepsy caused by MTS usually requires surgical treatment. Surgical techniques have gradually evolved in the last decades. Each approach and technique has advantages and disadvantages related to the potential lesion in the neocortex and
Table 4. Description of surgical complications.

\begin{tabular}{ll}
\hline Complications & $\mathrm{n}$ \\
\hline Cerebrospinal fluid Leakage & 1 \\
Oculomotor palsy & 2 \\
Internal capsule ischemia & 1 \\
\hline
\end{tabular}

Table 5. Cclinical results at 2 the two-years follow-up according to the Engel epilepsy surgery outcome scale.

\begin{tabular}{lc}
\hline Engel Class & $\mathrm{n}(\%)$ \\
\hline Class I - seizure free & $86(71)$ \\
Class II - reduction $>90 \%$ & $26(21.6)$ \\
Class III - reduction $60 \%-90 \%$ & $8(6.6)$ \\
Class IV - reduction $<60 \%$ & - \\
Class $V$ - no improvement & - \\
\hline
\end{tabular}

temporal substance of the temporal lobe, cerebral retraction and manipulation of vascular structures ${ }^{13}$.

The most commonly-used surgical technique is the anteromedial temporal lobectomy associated with hippocampectomy ${ }^{7,9,14}$. The complications of this technique result from lateral temporal neocortex resection (verbal, visual, cognitive and memory deficits), especially when the surgery is performed in the dominant hemisphere. Other frequent complications are: infection, ischemia, contralateral hemiparesis attributed to intraoperative cerebral retraction, oculomotor nerve palsy attributed to surgical manipulation, and cosmetic defects (attributed to the extent of craniotomy and temporal muscle atrophy $)^{14,15}$. An alternative method is selective amygdalohippocampectomy, a less-invasive procedure than the classical anterior temporal lobectomy ${ }^{16}$. The main advantages of this technique lie in less resection of the temporal neocortex.

A transsylvian approach requires accurate microsurgical technique because of the risk of vascular lesions. It is necessary 
to transect the temporal white matter with risk of injury to the uncinate fascicle that contains fibers that connect the frontal and temporal lobes ${ }^{8,10}$. The transcisternal approach requires dissection of basal cisterns and manipulation of neural and vascular structures of the tentorial hiatus ${ }^{17}$.

The subtemporal route requires a significant retraction of the temporal lobe with risk of injury to the Labbé vein, and delivers a restricted surgical field ${ }^{18}$. The lateral transtemporal approach transects the upper or middle temporal gyrus, with potential damage to the fibers of the optical radiation located on the lateral wall and roof of the temporal horn, resulting in superior quadrantanopsia in up to $50 \%$ of patients ${ }^{19,20,21,22}$. Most techniques of selective amygdalohippocampectomy require an extensive craniotomy, with additional morbidity. It is believed that the lateral transtemporal and transventricular amygdalohippocampectomy approaches (through corticectomy in the middle temporal gyrus) provide direct and safe resection of temporal mesial structures ${ }^{16,23}$.

In the lateral transtemporal route, through the middle temporal gyrus, lesion of the optical radiation may be avoided or minimized if access to the lateral horn of the lateral ventricle is performed in the anteroinferior part of the lateral wall of the temporal horn, due to the absence or less fiber density of the optical radiation in this region ("free area") ${ }^{12}$. In order to access this "free area" safely, it is useful to locate the craniometric projection point of the hippocampus head into the temporal bone ("hippocampal point" $)^{11}$. This craniometric point is located at a mean of $32 \mathrm{~mm}$ cranially to the external auditory canal.

A small craniotomy centered on the "hippocampal point" allows exposure of the medial temporal gyrus and an adequate exposure of the head and hippocampal body. This craniotomy
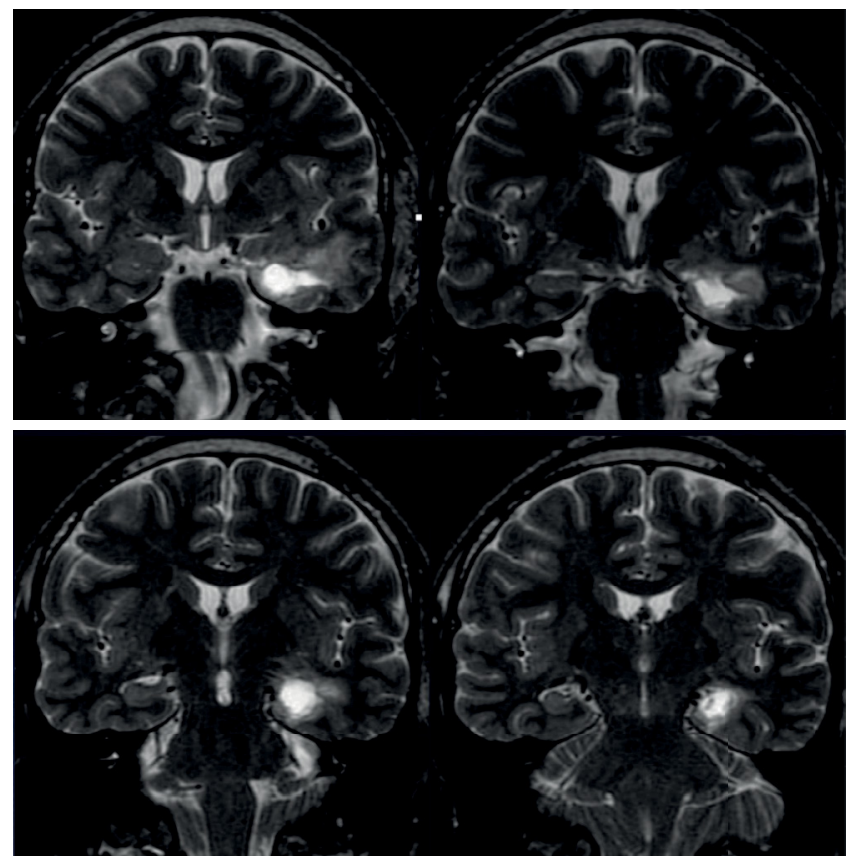

Figure 12. Brain MRI at the two-year follow-up, illustrating the resection of mesial structures with preservation of temporal neocortex. avoids injury to the frontal branch of the facial nerve and prevents cosmetic defects due to temporal muscle atrophy ${ }^{13,24}$.

In this series, the comparison between the groups showed that the mean surgical time reduced from 2.51 hours (group 1, first 70 patients) to 1.62 hours (group 2, last 50 patients), especially when compared to conventional techniques (five to seven hours). Shorter surgical time results in savings of surgical and anesthetic materials, and reduces additional invasive procedures. Usually, central venous catheters or bladder catheters are not necessary. In the last 50 patients, the use of rigid cranial fixation was unnecessary. Shorter surgical time also allows for the performance of two to three surgeries daily. We believe these advantages are important, especially in health care systems with limited resources.

Morbidity in this series was 3.3\% (one patient with incisional cerebrospinal fluid leakage, two with transient paresis of the oculomotor nerve and one with hemiparesis secondary to capsular ischemia. We attribute this complication to the use of bipolar cauterization near the entorhinal groove during the uncus removal. Eighty-six patients $(71 \%)$ were considered "seizure free" (Engel Outcome Scale Class I). Congruence between the epileptic focus and hippocampal atrophy in MRI was observed in all patients. Therefore, this technique afforded good-to-excellent clinical results.

Postoperative radiological examinations revealed adequate resection of mesial temporal structures. In the outpatient evaluations, patients did not spontaneously report any visual changes, and no field-related alterations were detected in the visual field examinations. Conversely, patients operated on with conventional techniques have had visual field disorders due to injury to the optic radiation ${ }^{20,22}$. With this technique, lateral temporal neocortex white fiber lesions are minimized (Figure 13). There is no

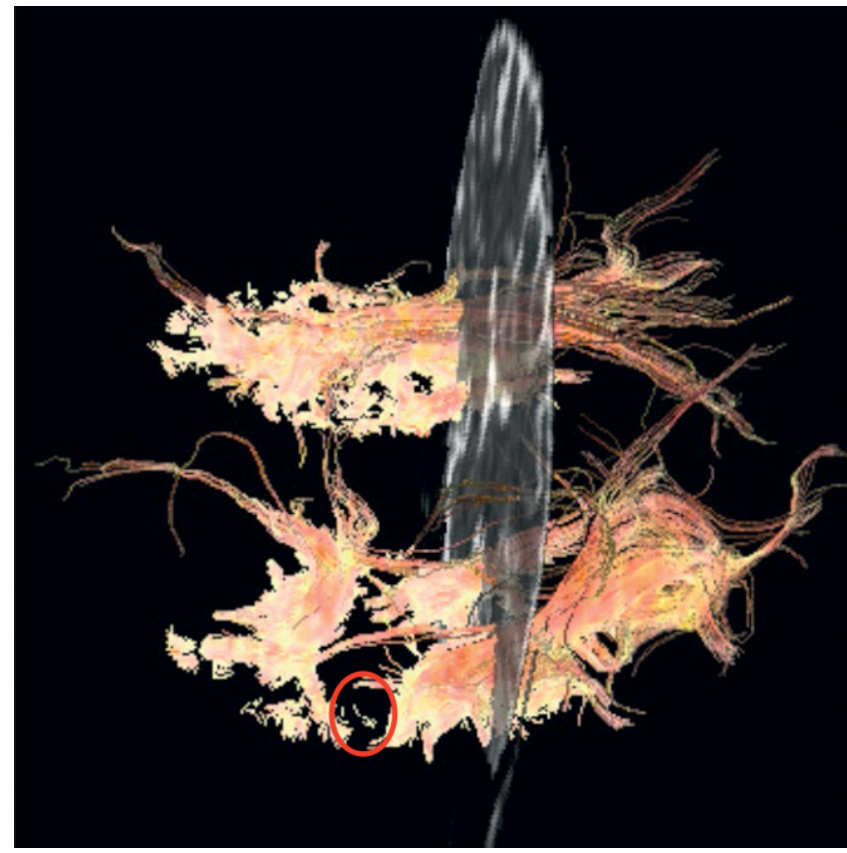

Figure 13. Postoperative MRI tractography with reconstruction of the optical radiation fibers. Area of corticectomy (oval) highlighted, illustrating the area of corticectomy and preservation of optical radiation fibers. 
neurophysiological study that defines the exact function of the middle temporal gyrus. Therefore, it is not possible to rule out repercussions in social and interpersonal interactions after its neocortex resection.

Temporal muscle atrophy (asymmetry relative to the contralateral side) was observed in six patients (5\%). Patients operated on by conventional techniques may present with unsatisfactory cosmetic outcomes, due to bone removal and temporal muscle atrophy from aggressive dissection.
In conclusion, the minimally-invasive technique presented has advantages that include reduced cutaneous-muscular incision, small craniotomy size, a cylindrical surgical corridor in the inferior and anterior part of the temporal gyrus and subpial resection of the mesial structures. It is a safe, less-invasive technique that provides adequate seizure control. It has low morbidity and low cost. It is reproducible and provides an adequate cosmetic result. It may be added to the surgical arsenal used to perform selective amygdalohippocampectomy.

\section{References}

1. Kale R. Bringing epilepsy out of the shadows. BMJ. 1997;315(7099):2-3. https://doi.org/10.1136/bmj.315.7099.2

2. Margerison JH, Corsellis JA. Epilepsy and the temporal lobes. A clinical, electroencephalographic and neuropathological study of the brain in epilepsy, with particular reference to the temporal lobes. Brain. 1966;89(3):499-530. https://doi.org/10.1093/brain/89.3.499

3. Hauser WA. The natural history of temporal lobe epilepsy. Epilepsy surgery. New York: Raven Press; 1991. p. 133-41.

4. Almeida Filho N, Pinho AR, Sampaio AP, Andrade Filho AS, Queiroz AC, Ribeiro BS et al. Epidemiologia social das epilepsias no Brasil: novas achegas sobre a epilepsia. Salvador: Centro Editorial e Didático de UFBA; 1980. p. 57-77.

5. Placencia M, Shorvon SD, Paredes V, Bimos C, Sander JW, Suarez $\mathrm{J}$ et al. Epileptic seizures in an Andean region of Ecuador. Incidence and prevalence and regional variation. Brain. 1992;115(3):771-82. https://doi.org/10.1093/brain/115.3.771

6. Clusmann H, Schramm J, Kral T, Helmstaedter C, Ostertun B, Fimmers R et al. Prognostic factors and outcome after different types of resection for temporal lobe epilepsy. J Neurosurg. 2002;9(5)7:1131-41. https://doi.org/10.3171/jns.2002.97.5.1131

7. Elliott RE, Bollo RJ, Berliner JL, Silverberg A, Carlson C, Geller EB et al. Anterior temporal lobectomy with amygdalohippocampectomy for mesial temporal sclerosis: predictors of long-term seizure control. J Neurosurg. 2013;119(2):261-72. https://doi.org/10.3171/2013.4.JNS121829

8. Vajkoczy P, Krakow K, Stodieck S, Pohlmann-Eden B, Schmiedek P. Modified approach for the selective treatment of temporal lobe epilepsy: transsylvian-transcisternal mesial en bloc resection. J Neurosurg. 1998;88(5):855-62. https://doi.org/10.3171/jns.1998.88.5.0855

9. Wiebe S, Blume WT, Girvin JP, Eliasziw M. A randomized, controlled trial of surgery for temporal-lobe epilepsy. N Engl J Med. 2001;345(5):311-8. https://doi.org/10.1056/NEJM200108023450501

10. Yașargil MG, Wieser HG, Valavanis A, Ammon K, Roth P. Surgery and results of selective amygdala-hippocampectomy in one hundred patients with nonlesional limbic epilepsy. Neurosurg Clin N Am. 1993;4(2):243-61.

11. Olmo TS, Roelke CE, Farias MH. Lateral approach for amigdalohippocampectomy: morphometric data based on MRI and CT scans. Braz Neurosur. 2013;32:11-4.

12. Silva RC, Flores JAC, Aguiar GB, Cannoni LF, Duarte M, Barros JCEV. Anatomic study of the optical radiation and its relationship in the temporal lobe: definition of a secure approach for amigdalohipocampectomy in epilepsy surgery.

Rev Chil Neurocirugía. 2014;40:8-11.

13. Duckworth EA, Vale FL. Trephine epilepsy surgery: the inferior temporal gyrus approach. Neurosurgery. 2008;63(1 Suppl 1):ONS156-60.

14. Clusmann H, Kral T, Gleissner U, Sassen R, Urbach H, Blümcke I et al. Analysis of different types of resection for pediatric patients with temporal lobe epilepsy. Neurosurgery. 2004;54(4):847-59. https://doi.org/10.1227/01.NEU.0000114141.37640.37

15. Hori T, Yamane F, Ochiai T, Kondo S, Shimizu S, Ishii K et al. Selective subtemporal amygdalohippocampectomy for refractory temporal lobe epilepsy: operative and neuropsychological outcomes.J Neurosurg. 2007;106(1):134-41. https://doi.org/10.3171/jns.2007.106.1.134

16. Niemeyer P. The transventricular amygdalohippocampectomy in temporal lobe epilepsy. In: Baldwin M, Bailey P, editors. Temporal lobe epilepsy. Springfield: Charles C. Thomas; 1958. p. 461-82.

17. Figueiredo EG, Deshmukh P, Nakaji P, Crusius MU, Teixeira MJ, Spetzler RF et al. Anterior selective amygdalohippocampectomy: technical description and microsurgical anatomy. Neurosurgery. 2010;66(3 Suppl Operative):45-53. https://doi.org/10.1227/01.NEU.0000350981.36623.8B

18. Hori T, Tabuchi S, Kurosaki M, Kondo S, Takenobu A, Watanabe T. Subtemporal amygdalohippocampectomy for treating medically intractable temporal lobe epilepsy. Neurosurgery. 1993;33(1):50-6. https://doi.org/10.1097/00006123-199307000-00008

19. Bender DB. Retinotopic organization of macaque pulvinar. J Neurophysiol. 1981;46(3):672-93.

20. Björk A, Kugelberg E. Visual field defects after temporal lobectomy. Acta Ophthalmol (Copenh). 1957;35(3):210-6. https://doi.org/10.1111/j.1755-3768.1957.tb05407.x

21. Egan RA, Shults WT, So N, Burchiel K, Kellogg JX, Salinsky M. Visual field deficits in conventional anterior temporal lobectomy versus amygdalohippocampectomy. Neurology. 2000;55(12):1818-22. https://doi.org/10.1212/WNL.55.12.1818

22. Meyer A. The connections of the occipital lobes and the present status of the cerebral visual affections. Trans Assoc Am Physicians. 1907;22:7-16.

23. Tanriverdi T, Olivier A, Poulin N, Andermann F, Dubeau F. Long-term seizure outcome after mesial temporal lobe epilepsy surgery: corticalamygdalohippocampectomy versus selective amygdalohippocampectomy. J Neurosurg. 2008;108(3):517-24. https://doi.org/10.3171/JNS/2008/108/3/0517

24. Olivier A. Transcortical selective amygdalohippocampectomy in temporal lobe epilepsy. Can J Neurol Sci. 2000;27 Suppl 1:S68-76. 